\title{
El escepticismo profesional del auditor. Una visión desde los docentes de contaduría pública colombianos*
}

\author{
The Professional Skepticism of the Auditor. A vision from Colombian Public Accounting teachers \\ O ceticismo profissional do auditor. Uma visão dos professores colombianos de contabilidade pública
}

\author{
Norka Viloria Ortega \\ Universidad de Los Andes, Venezuela \\ ORCID: https://orcid.org/0000-0002-1735-947X \\ Yuli Samary Espinosa Díaz ${ }^{\text {a }}$ \\ Universidad Santo Tomás, Colombia \\ yulisamary@gmail.com \\ ORCID: https://orcid.org/0000-0002-8849-7423
}

DOI: https://doi.org/10.11144/Javeriana.cc21.epav

Recibido: 01 Enero 2019

Aceptado: 10 Junio 2020

Publicado: 19 Diciembre 2020

\section{Resumen:}

Este artículo tiene como objetivo presentar estrategias de salón de clase para la formación del escepticismo profesional en estudiantes de contaduría pública, basadas en la percepción de los docentes en Colombia. La investigación, de tipo cualitativo, fue realizada a través de una entrevista semi-estructurada a 15 docentes del área de auditoría en instituciones de educación superior en Colombia. Los participantes también son contadores públicos en ejercicio de su profesión. Dentro de las estrategias propuestas por los docentes se encuentran el estudio de caso, el juego de roles, y la revisión curricular como mecanismos para la formación el escepticismo en auditorías. Se considera que reforzar el escepticismo profesional en la formación universitaria de los Contadores Públicos permite lograr un profesional integral e íntegro, capaz de buscar evidencias suficientes y adecuadas en función de su juicio crítico.

Código JEL: M40, M42.

Palabras clave: Escepticismo profesional, formación, estrategias.

\section{Abstract:}

This article aims to present classroom strategies for the formation of professional skepticism in public accounting students, based on teachers' perceptions in Colombia. A qualitative study using a semi-structured interview was conducted in a sample of 15 teachers of audit area in higher education institutions in Colombia. Participants are also practicing public accountants. Among the strategies proposed by the teachers, it can be found case studies, role plays, and curricular revision as mechanisms to train in audit skepticism. It is believed that reinforcing professional skepticism in public accountants allows achieving a comprehensive and upright professional, capable of seeking sufficient and adequate evidence based on its critical judgment.

\section{JEL Codes: M40, M42.}

Keywords: Professional skepticism, training, strategies.

\section{Resumo:}

Este artigo tem como objetivo apresentar estratégias em sala de aula para a formação do ceticismo profissional em estudantes de contabilidade pública, com base na percepção dos professores na Colômbia. A pesquisa, de natureza qualitativa, foi realizada por meio de uma entrevista semiestruturada a 15 docentes da área de auditoria em instituições de ensino superior da Colômbia. Os participantes também são contadores públicos em exercício de sua profissão. Entre as estratégias propostas pelos professores estão o estudo de caso, a dramatização e a revisão curricular como mecanismos para a formação do ceticismo nas auditorias. Considera-se que o reforço do ceticismo profissional na formação universitária de Contadores Públicos permite gerar um profissional abrangente e honesto, capaz de buscar evidências suficientes e adequadas com base no seu juízo crítico.

Código JEL: M40, M42.

Palavras-chave: Ceticismo profissional, treinamento, estratégias.

Notas de autor

\footnotetext{
${ }^{\text {a }}$ Autora de correspondencia. Correo electrónico: yulisamary@gmail.com
} 


\section{Introducción}

La formación académica de un contador público se relaciona con aspectos disciplinares y técnicos, desarrollo de habilidades, y un conjunto de actitudes (éticas, valores, y comportamiento profesional) que fortalecen de forma apropiada la conducta profesional. Entre las actitudes se aspira que se apliquen en el ejercicio profesional y, en especial, en la actividad de aseguramiento y auditoría. Entre estas se encuentra el escepticismo profesional. La Norma Internacional de Auditoría -NIA- 200 define al escepticismo profesional como una "actitud que implica una mentalidad inquisitiva, una especial atención a las circunstancias que puedan ser indicativas de posibles incorrecciones debidas a errores o fraudes, y una valoración crítica de la evidencia de auditoría" (IAASB en IFAC, 2017, párrafo 13-1, p. 85).

El escepticismo profesional es un elemento crucial en las decisiones del auditor, desde la planeación y ejecución del encargo (incluida la determinación de los riegos) hasta la decisión sobre el tipo de opinión que emitirá. El escepticismo profesional es aplicado por los auditores al mantener una actitud de cuestionamiento acerca de las aserciones de la gerencia sobre sus informes financieros. Esta actitud lo mantiene alerta ante inconsistencias, omisiones o errores, y le permite a través de un pensamiento crítico, tomar decisiones que tienden a minimizar los riesgos en la actuación profesional.

A pesar de la importancia del escepticismo profesional, no existen consensos entre los organismos internacionales emisores de normas internacionales ni entre investigadores sobre las definiciones, alcances y formación del escepticismo profesional. Los diferentes Consejos emisores de norma internacional han conformado grupos de trabajo para aclarar y llegar acuerdos en este tema y ser consistentes en todos los cuerpos normativos. Por otra parte, entre los investigadores, el punto de discusión es como entender y formar el escepticismo profesional.

En cuanto a las investigaciones en escepticismo existen varias tendencias. En este artículo se confrontan los planteamientos de Hurtt et al. (2002, 2008, 2010, 2013), y Nelson (2009), como referentes teóricos, contrapuestos. Para el primer grupo de autores, el escepticismo profesional se relaciona con una mentalidad cuestionadora que se relaciona con cualidades personales, que a su vez configuran una actitud profesional. Por tanto, la formación del contador público debe enfocarse a reforzar estas actitudes. Para el segundo autor, el escepticismo se relaciona con tres elementos: información, personalidad e incentivos, los cuales condicionan una actitud de duda presunta y configuran lo que el autor denomina juicio escéptico. Los esfuerzos de formación se deben centrar en el logro de un juicio escéptico que está influenciado por el manejo de los incentivos por parte del profesional.

En este sentido, es de interés de este artículo la formación en las aulas de clases del escepticismo profesional. $\mathrm{Su}$ intención principal es presentar estrategias de aula para la formación de esta actitud en estudiantes de contaduría pública, a partir de las opiniones de los docentes del área de auditoría, en instituciones de educación superior en Colombia. Se trata de una investigación con enfoque cualitativo que explora la existencia de diferentes posturas para concebir el escepticismo profesional y como éstas pueden incidir en la formación del contador público. En este sentido, se parte de la identificación de estas posturas entre los docentes para, luego, explicar las estrategias de aula propuestas.

Los resultados de esta investigación muestran que, a pesar de la identificación de un grupo de docentes con la tendencia de cuestionamiento mental y de otros con la de duda presunta, al proponer estrategias de formación del escepticismo, ambos coinciden en estudios de casos y juegos de roles. Se destaca como estrategia fundamental, la revisión del currículo de formación del contador público. Esto implica integrar como eje transversal el escepticismo profesional, así como reforzar los aspectos de formación investigativa, lectura disciplinar y educación en valores.

Este artículo consta de cinco secciones aparte de esta introducción. La primera sección corresponde al contexto problemático, que trata de la problemática de la formación del escepticismo profesional; la segunda sección comprende la revisión teórica, en la que se relacionan los planteamientos de los autores seleccionados 
y la normatividad internacional; en la tercera sección se explica la metodología, en la que se explica el proceso investigativo; la cuarta sección de hallazgos explica los resultados más significativos. Finalmente, se presentan las conclusiones y recomendaciones.

\section{Contexto problemático}

El escepticismo profesional es un aspecto crucial para el contador público en función de la actividad de auditoría. A pesar de la importancia del escepticismo profesional y su vinculación con las diferentes situaciones adversas que amenazan la actuación profesional, no se ha hecho un énfasis para su definición, aplicación adecuada, ni su formación en el contador público (Hurtt et al., 2013).

La preocupación sobre la definición y adecuado uso del escepticismo profesional ha sido reconocida por la Federación Internacional de Contadores (IFAC, por sus siglas en inglés). Este organismo integra a tres de sus consejos: el Consejo de Estándares de Auditoría y Aseguramiento (IAASB, por sus siglas en inglés), el Consejo de Estándares de Ética (IESBA por sus siglas en inglés) y el Consejo de Estándares de Educación (IAESB, por sus siglas en inglés), para que trabajen en forma conjunta en el tema, y contribuyan "al entendimiento y aplicación del concepto de escepticismo profesional en una auditoría” (IFAC, 2017, p. 2). Se entiende, por parte del organismo que, en la auditoría, el escepticismo profesional es una parte fundamental en la formación del juicio profesional.

Los consejos de estándares plantean la necesidad de tomar consciencia del entendimiento de los rasgos personales del profesional contable y las externalidades que afectan al escepticismo. Se reconoce, además, la necesidad de que en el proceso de formación del contador público se desarrolle una actitud escéptica. Aunque los temas de definición y adecuado ejercicio del escepticismo profesional son importantes, este artículo se enfoca en los procesos de formación de este en la etapa de titulación profesional.

La educación del contador público, en su primera etapa de titulación, se lleva a cabo en instituciones de educación superior, y se enfoca en competencias técnicas, habilidades profesionales, valores, ética y actitudes. De esta forma, la Norma Internacional de Educación -NIE- 2 incluye al escepticismo profesional como una competencia relacionada con los valores. La norma expresa que "dentro de los valores profesionales, la ética y las actitudes incluyen principios éticos, así como el escepticismo profesional y juicio profesional”. (IAESB, 2019, párrafo A5, p. 38).

El juicio profesional y escepticismo profesional son conductas inherentes y relacionadas en el contador público en ejercicio como auditor. El juicio profesional conjuga conocimientos, experiencias y principios éticos. En ese marco, el escepticismo profesional se relaciona con una actitud de cuestionamiento y duda frente a las evidencias recopiladas, ya que, al colocar en duda una evidencia, se afecta el juicio profesional. El escepticismo influye en la decisión que tome el profesional frente a la evidencia. Nelson (2009) denomina a esta relación juicio escéptico.

El juicio escéptico es un atributo del profesional desarrollado al valorar y analizar las evidencias. Esto deriva en acciones escépticas (Nelson, 2009). Es decir, a medida que se evalúa la información, el auditor toma decisiones utilizando su juicio profesional (que, el autor, califica como crítico) e implementa nuevos procedimientos para cotejar y validar las pruebas (acciones). En este sentido, para el autor hay dos elementos fundamentales que deben reconocerse: el juicio escéptico (la conjunción del juicio profesional y escepticismo profesional) y la acción que se genera.

Desde esta perspectiva se debe incidir en el proceso de enseñanza profesional del contador público, en ambos aspectos. Para la formación del juicio escéptico se pueden desarrollar ciertas habilidades en el manejo de las pruebas de auditoría (McCoy et al., 2011), mientras que para la acción escéptica debe hacerse más énfasis en los temas éticos. Al combinar habilidades y conducta ética "los estudiantes tendrán un modo de pensar más escéptico, al acercarse a las evidencias de auditoría o identificando un fraude potencial.” (Liu, 2018, p. 4). 
Otros investigadores como Hurtt, Eining y Plumlee (2008), plantean que el escepticismo profesional se relaciona con rasgos de personalidad y las condiciones del encargo de auditoría. Para los autores, dependiendo de la situación que se presente, el profesional tomará una actitud o acción como consecuencia del hecho. Por lo tanto, la conducta o comportamiento son rasgos propios de cada persona, los cuales pueden diferir de una a otra. De ahí la importancia de generar en los estudiantes un pensamiento crítico que motive a cuestionar e indagar cuidadosamente, sobre las evidencias que recopile.

En esta perspectiva, la formación del escepticismo profesional en la etapa de titulación se centraría en el reforzamiento de los rasgos de personalidad que más inciden en mantener una actitud de duda, tales como mente inquieta, suspensión del juicio, búsqueda de conocimiento, entendimiento interpersonal, autonomía y autoestima (Hurtt, 2010).

En estas dos posiciones teóricas y en los requerimientos de la NIE se investiga sobre estrategias de aula para la formación del escepticismo profesional, desde la perspectiva de los docentes. Esto debido a que "los auditores tienen y están continuamente siendo educados para ser profesionales que deben juzgar y decidir, de acuerdo con estándares profesionales" (Quadackers, 2009, p. 14). Pareciera necesario hacer del escepticismo profesional un eje transversal en la formación del contador, utilizando diferentes estrategias para desarrollar la competencia de cuestionar hechos y circunstancias y, así, evaluar críticamente los resultados. El escepticismo profesional debe formarse en la etapa de titulación del profesional como una cualidad que usará constantemente en los encargos de trabajo que asuma como contador público, en especial, en la actividad de auditoría (Viloria, 2013).

\section{Revisión Teórica}

La normativa internacional de la profesión contable incluye diversas referencias al escepticismo profesional, de forma directa e indirecta. Para la IFAC (2017), a través del grupo de trabajo combinado, existen tres áreas prioritarias relacionadas con escepticismo profesional: las Normas Internacionales de Auditoría y Aseguramiento de la Información (NIAA), el Código Internacional de Ética para Profesionales de la Contabilidad (Incluidas Normas Internacionales de Independencia) (acepta la denominación de "el Código"), y las NIE. En la tabla 1 se muestra un resumen de sus planteamientos.

TABLA 1

Áreas prioritarias que incluyen escepticismo profesional

\begin{tabular}{|l|l|}
\hline \multicolumn{1}{|c|}{ Área } & \multicolumn{1}{c|}{ Descripción } \\
\hline $\begin{array}{l}\text { Control de calidad y NIAA } \\
\text { (Riesgos para la calidad, } \\
\text { incluidos los sesgos del } \\
\text { auditor, cultura y la } \\
\text { conformación de equipos de } \\
\text { auditoria) }\end{array}$ & $\begin{array}{l}\text { Reconoce, el grupo combinado, que la Norma Internacional } \\
\text { de Control de Calidad 1 (IAASB, 2017) no indica } \\
\text { expresamente la necesidad del escepticismo profesional, sin } \\
\text { embargo, en cada requerimiento de calidad de la firma ored } \\
\text { de firmas, establece la necesidad de un juicio profesional, } \\
\text { con base en las normas y principios éticos, y para lograrlo se } \\
\text { requiere de escepticismo profesional. } \\
\text { El auditor en la planificación y a lo largo de su trabajo debe } \\
\text { utilizar el escepticismo profesional al realizar juicios acerca de } \\
\text { las evidencias relacionadas con las estimaciones contables,y } \\
\text { cómo éstas afectan los riesgos asociados de la auditoria. }\end{array}$ \\
\hline Interés Público & $\begin{array}{l}\text { El Código Internacional de Ética para Profesionales de la } \\
\text { Contabilidad (incluidas Normas Internacionales de } \\
\text { Independencia)(IESBA, 2018, párrafo 1, p. 6), expresa que } \\
\text { "establece principios fundamentales de ética para } \\
\text { profesionales de la contabilidad, lo cual refleja el } \\
\text { reconocimiento de la profesión hacia su responsabilidad con } \\
\text { el interés público." Actuar bajo los principios éticos implica } \\
\text { la aplicación adecuada del escepticismo profesional, y como } \\
\text { lo declara el Código (IESBA, 2018, párrafo 120.13 Al, p. } \\
\text { 27) "El escepticismo profesional y los principios } \\
\text { fundamentales que se describen en la sección 110 son } \\
\text { conceptos interrelacionados". }\end{array}$ \\
\hline Educación & $\begin{array}{l}\text { La necesidad de apoyar los procesos educativos para lograr las } \\
\text { mejores prácticas en cuanto al escepticismo profesional, en } \\
\text { función de cumplir con los requisitos normativos y con las } \\
\text { necesidades y expectativas de los usuarios de la información. }\end{array}$ \\
(NIE) &
\end{tabular}

Fuente: elaboración propia con base en IFAC (2017). 
En la tabla 1 se observa la vinculación del escepticismo profesional en tres áreas fundamentales: la calidad del trabajo y normas de aseguramiento y auditoría; el interés público, como propósito fundamental de la profesión; y las normas de educación, como parte del proceso de formación. Estos aspectos convergen de forma simultánea en el escepticismo profesional en la medida en que mantener una conducta escéptica tiende a disminuir riesgos en la recopilación de evidencias y la toma de decisiones del contador.

La primera área, de la tabla 1, se refiere a las Normas Internacionales de Aseguramiento y Auditoría NIAA-. Como es expresado por la IFAC (2017), a lo largo de todas las normativas se incorpora la aplicación del escepticismo profesional como un requerimiento. A manera de ejemplo, la NIA 200 prevé que "el auditor planificará y ejecutará la auditoría con escepticismo profesional, reconociendo que pueden darse circunstancias que supongan que los estados financieros contengan incorrecciones materiales" (IAASB, 2017, párrafo 15, p. 86). Es decir, el escepticismo se aplica desde la planificación hasta la elaboración del dictamen, como una conducta de cuestionamiento de las evidencias y resultados obtenidos. Sin embargo, esto no es explicado de forma detallada.

La segunda área de la tabla 1 se refiere al propósito de la profesión de servir al interés público. Esto está ratificado en el Código (IESBA, 2018), el cual incluye al escepticismo profesional como un requerimiento asociado a los principios éticos fundamentales. Explica el Código que,

En virtud de las normas de auditoría, revisión y otros estándares de seguridad, incluidos los emitidos por el IAASB, los contadores profesionales en la práctica pública deben ejercer escepticismo profesional al planificar y realizar auditorías, revisiones y otros compromisos de aseguramiento. (IESBA, 2018, párrafo, 120-13 A1, p. 26)

Dada la importancia del requerimiento, el Código (IESBA, 2018) establece algunas acciones esperadas del ejercicio de escepticismo profesional vinculadas a los principios éticos fundamentales. En la tabla 2, se resume la vinculación de los principios éticos, tales como: integridad, objetividad, competencia profesional y debido cuidado, y las conductas esperadas del profesional que aplica el escepticismo profesional.

TABLA 2

Principios éticos y conductas esperadas en ejercicio del escepticismo profesional

\begin{tabular}{|l|l|}
\hline \multicolumn{1}{|c|}{ Principios } & Características del escepticismo profesional \\
\hline Integridad & $\begin{array}{l}\text { Directo y honesto ante la postura de un cliente. } \\
\text { Investigar inconsistencias. } \\
\text { Tomar decisiones informadas. } \\
\text { Evaluación crítica de la evidencia. }\end{array}$ \\
\hline Objetividad & $\begin{array}{l}\text { Reconocimiento de circunstancias que } \\
\text { comprometan el juicio profesional. } \\
\text { Consideración de los impactos de } \\
\text { circunstancias y relaciones que afecten la } \\
\text { evaluación de riesgos. }\end{array}$ \\
\hline Competencia profesional & $\begin{array}{l}\text { Conocimiento de las actividades del cliente para } \\
\text { identificar de forma apropiada los riesgos de } \\
\text { declaraciones inadecuadas. } \\
\text { D debido cuidado }\end{array}$ \\
& $\begin{array}{l}\text { Diseño y aplicación de procedimientos de auditoria } \\
\text { Evaluación crítica de las evidencias y hallazgos. }\end{array}$ \\
\hline
\end{tabular}

Fuente: elaboración propia con base en el párrafo 120.13 A2 del Código Internacional de Ética para Profesionales de la Contabilidad. (IESBA, 2018).

El tercer aspecto, se relaciona con las normas de educación. La NIE 2 (IAESB, 2019, p. 22) define al escepticismo profesional como "una actitud que incluye una mente inquisitiva, estar alerta a las condiciones que pueden indicar una posible representación errónea debido a un error o fraude, y una evaluación crítica de la evidencia”. La actitud se refiere al modo de enfrentar situaciones específicas, y el juicio crítico, a la posibilidad de evaluación de las evidencias con independencia y objetividad.

La NIE 4 (IAESB, 2019) propone el alcance de dos resultados tangibles, en razón a la competencia en valores (en la que incluye el escepticismo): aplicar un modo de pensar que cuestione la información financiera y evaluar alternativas de acciones para llegar a conclusiones pertinentes. La NIE 4 (IAESB, 2019) explica que 
temas como el escepticismo profesional deben ser tratados y fomentados en diversas materias a lo largo de la carrera profesional. Además,

El desarrollo profesional en las áreas de escepticismo profesional y juicio profesional no siempre es sencillo. La planificación de aprendizaje y desarrollo eficaz en estas áreas implica el debido cuidado y puede incluir los métodos de aprendizaje en el que la tutoría, la actividad reflexiva, el tiempo y la experiencia práctica juegan un papel clave. (IAESB, 2019, párrafo A27, p. 62)

Es importante, resaltar que el campo normativo no ha especificado características o acciones a considerar que deben formarse más allá del cuestionamiento y la evaluación crítica de las evidencias. "Ser escéptico a menudo tiene que ver con cuestionamiento, observación cuidadosa, reflexión y suspensión de la creencia. El escepticismo profesional incorpora atributos asociados con un ser escéptico a un profesional que requiere de estándares de diligencia debida y cuidado." (Glover \& Prawitt, 2014, p. 2). Ambas características -diligencia y cuidado- deben desarrollarse para alcanzar el desarrollo del escepticismo profesional.

Existen diversas tendencias sobre escepticismo profesional. En esta investigación se toma como base las tendencias de la duda presunta (Nelson, 2009) y la del cuestionamiento (Hurtt et al., 2010).

En la tendencia de cuestionamiento, Hurtt et al. (2002) plantean tres rasgos del auditor escéptico: los relacionados con la personalidad, con la forma de realizar el trabajo y con el manejo de la información. Además, los autores defienden que estos rasgos pueden ser medidos y formados en los profesionales para lograr una mentalidad cuestionadora. Esta posición puede verse en el campo normativo, el cual entiende el escepticismo profesional como el cuestionamiento constante de los hechos presentados en la información financiera.

Adicionalmente, Hurtt et al. (2008) definieron una escala para medir los rasgos de personalidad con las siguientes variables: curiosidad, confianza en sí mismo, entendimiento personal, cuestionamiento, autodeterminación y deliberación. Estas características permiten valorar qué tan escéptico es el profesional en la medida que su personalidad contenga estos rasgos.

En la tendencia de la duda presunta, se diferencia juicio escéptico y actitud escéptica (Nelson, 2009). Para el autor, el juicio del auditor se forma con información, aunque también inciden las características de su personalidad y sus incentivos. La combinatoria de la información (del cliente, de las leyes y la normatividad contable, por ejemplo), de la personalidad (tendencia a la duda, capacidad de resolución de conflictos, entre otros) y de los incentivos (mantener al cliente, bonos de productividad, entre otros) produce una acción que se refleja en la cantidad y tipos de pruebas de auditoría. Los esfuerzos deben dirigirse a la formación del juicio escéptico, en las tres áreas (información, personalidad e incentivos).

Según Nelson (2009), en un encargo, se inicia bajo el supuesto de que la información entregada por el cliente está libre de error. Es allí en donde el auditor debe aplicar la duda presunta para practicar procedimientos que generen evidencia relativa o suficiente sobre los hechos informados, de manera que las pruebas presentadas sean eficientes en términos de calidad y cantidad. El modelo de Nelson (2009) también propone una serie de aspectos necesarios para llevar a cabo la auditoría con alto grado de escepticismo, tales como el conocimiento del cliente, la alta evaluación de riesgos, la alta duda sobre la veracidad de las pruebas, la resolución de problemas y la capacidad para detectar declaraciones falsas e incentivos.

En lo que coinciden ambas tendencias es que el juicio escéptico debe ser el eje transversal en la formación del contador público (Libby \& Luft, 1993). Además, debe practicarse en cada procedimiento de auditoría (McCoy et al., 2011). Es decir, el escepticismo profesional debe usarse constantemente a lo largo de la vida profesional, y sus características deben vincularse a la formación profesional (Viloria, 2013; 2016).

Las dos tendencias demuestran ventajas y desventajas. Si se asume la posición de mentalidad cuestionadora debe pensarse en una selección previa sobre las características personales de quién desee titularse como contador público, lo cual podría entenderse como discriminatorio. Sin embargo, esta tendencia tiene la ventaja de que, al manifestar las características, se pueden desarrollar estrategias puntuales de formación, por ejemplo, en áreas como la autoestima. Si se asume la posición de duda presunta, el peso de la decisión recae en 
la interioridad del profesional, por lo que es difícil conocer cuáles aspectos deben fortalecerse. Sin embargo, esta tendencia tiene la ventaja de integrar dos conceptos fundamentales como lo es el juicio profesional y el escepticismo profesional, en lo que se denomina como juicio escéptico.

\section{Metodología}

La presente investigación es analítica de tipo cualitativo. Se toma como referencia las posiciones y características sobre el escepticismo dadas por cuestionamiento, basado en las cualidades personales (Hurtt, Eining, \& Plumlee, 2008); y de duda presunta, mostrado a los docentes como confianza (Nelson, 2009); A partir de las posiciones de los entrevistados, se presentan las estrategias de aula. Se utiliza una entrevista semiestructurada, que contiene:

1. Dos preguntas cerradas y mutuamente excluyentes, referidas a la concepción del escepticismo profesional como un tema de confianza o de cualidad personal. Seguidamente, se solicita una justificación de las respuestas.

2. Dos preguntas de selección múltiple mutuamente excluyentes, relacionadas con las características a fomentar para formar el escepticismo profesional. Las alternativas se relacionan con las características de las dos tendencias: mentalidad cuestionadora (cualidades personales) y duda presunta.

3. Dos preguntas abiertas, referidas a otras características a fomentar en un profesional escéptico distintas a las mostradas en el instrumento y a las estrategias de aula propuestas.

El instrumento se validó a través de juicios de expertos de contenido y de metodología. Se aplicó en el año 2018, a través de encuentros con los informantes seleccionados. Los informantes clave corresponden a 15 docentes que cumplían las siguientes condiciones: que estuvieran dictado la unidad curricular de Auditoría y/o Aseguramiento, y que ejercieran profesionalmente en las mismas áreas. Geográficamente, se ubican en las ciudades colombianas de Bogotá, Medellín y Cali. Para resguardar la identidad de los docentes, se utilizó una codificación alfanumérica, utilizando la palabra "docente" y un número del 1 al 15. Se transcribieron todas las opiniones y se hizo un extracto para el artículo.

Los hallazgos se analizan a partir de la revisión teórica. Las respuestas se agrupan de acuerdo con el tipo de pregunta de la siguiente manera: en frecuencia simple (para preguntas dicotómicas), número de respuestas (para preguntas que permitían seleccionar varias alternativas), y contrastación de opiniones (preguntas abiertas). Los resultados se presentan en tablas, de acuerdo con la tendencia del escepticismo que manifiestan los docentes (mentalidad cuestionadora o duda). Posteriormente, se realiza el análisis por cada grupo. En cada tabla se hace mención del docente codificado y su respuesta, conservando la codificación asignada y el anonimato de cada individuo.

\section{Hallazgos}

A los entrevistados se les consultó sobre su posición del escepticismo profesional, utilizando las dos tendencias presentadas, en los referentes teóricos. En la percepción del escepticismo profesional como mentalidad cuestionadora (cualidades personales) se identificaron 6 docentes, 5 docentes se ubican en la tendencia de confianza (duda presunta), 2 docentes manifiestan no ser afines a ninguna de las dos, y 1 docente (docente 14) no contestó.

Seis docentes perciben el escepticismo profesional como una mentalidad cuestionadora, el escepticismo es relacionado con características propias de la persona, en consistencia con los referentes teóricos. Sin embargo, al justificarlo no lo asocian a las cualidades del profesional que deben desarrollarse. Varios de los entrevistados 
se sitúan en que esta cualidad es "propia de cada ser", es decir, hace parte de su personalidad. En la tabla 3 se muestran las justificaciones de su decisión de considerar el escepticismo profesional como un tema de cualidades personales, relacionado con la mentalidad cuestionadora.

TABLA 3

Opiniones de los docentes que perciben el escepticismo profesional como cuestionamiento (relacionado con cualidades)

\begin{tabular}{|c|c|}
\hline Docente & Opinión \\
\hline Docente 2 & $\begin{array}{l}\text { "En términos generales si yo lo que busco es generar condiciones para } \\
\text { que las organizaciones mejoren, y no sólo buscar o detectar errores, yo } \\
\text { creo que tanto el comportamiento como la confianza van ligados al } \\
\text { ejercicio profesional". }\end{array}$ \\
\hline Docente 5 & $\begin{array}{l}\text { "Hay personas que tienen características especiales y específicas que } \\
\text { hacen pensar que podia ser una buena auditoria". }\end{array}$ \\
\hline Docente 7 & $\begin{array}{l}\text { "El tema de escepticismo profesional es algo ya como de } \\
\text { características humanas y de condiciones de cada persona, porque los } \\
\text { profesionales actúan de acuerdo con sus fundamentos, con su } \\
\text { fundamentación teórica, como con lo que tienen su estructura } \\
\text { conceptual de acuerdo no sólo con lo que han aprendido en la } \\
\text { universidad, sino que también lo han aprendido en la casa". }\end{array}$ \\
\hline Docente 8 & $\begin{array}{l}\text { "Para mi, cualidad, porque es propia del ser, por eso y uno puede } \\
\text { determinar que, en algunos casos, podemos encontrar muchos perfiles } \\
\text { de auditores, y para mi un buen auditor es -entre otras cosas- una } \\
\text { persona que ha desarrollado un escepticismo profesional importante } \\
\text { para tomar decisiones". }\end{array}$ \\
\hline Docente 9 & $\begin{array}{l}\text { "Es esa actitud inquisidora, inquieta, curiosa, que debe tener el auditor } \\
\text { en el momento que hace su auditoria, no tanto hacia ese } \\
\text { cuestionamiento de que si yo estoy haciendo bien mi trabajo o no, } \\
\text { porque se supone que tengo una formación y partiendo de ahí hacemos } \\
\text { toda esta planeación". }\end{array}$ \\
\hline Docente 12 & $\begin{array}{l}\text { "Uno como auditor siempre tiene que estar latente en el escepticismo, } \\
\text { aquí no hay confianza, no hay desconfianza porque todo va a estar } \\
\text { dirigido a los estados financieros, a los hechos, a las transiciones, seria } \\
\text { el comportamiento del auditor (...), siempre hay que conservar el } \\
\text { escepticismo". }\end{array}$ \\
\hline
\end{tabular}

Fuente: elaboración propia con base en los resultados de las entrevistas.

Este grupo de entrevistados consideran que el escepticismo se relaciona con características de la personalidad, por lo que al poseerlas se puede ser mejor auditor; reconocen la importancia del escepticismo como parte esencial en todas las fases del trabajo de auditoría; y lo asocian a la adecuada conducta profesional. Sin embargo, ellos perciben las cualidades personales como previas a la formación, y no como susceptibles de ser desarrollarlas en los estudios universitarios.

Cinco docentes asocian el escepticismo a una relación de confianza/desconfianza, y lo entienden como desconfianza hacia las personas. Esto se aleja del criterio de Nelson (2009), que entiende el escepticismo como la puesta en duda de las aserciones de la gerencia sobre los informes financieros. Mientras los entrevistados enfocan la duda en lo que les inspira el cliente o su persona, la duda presunta en Nelson (2009) se relaciona con las transacciones y sus evidencias. En este sentido, el enfoque adoptado por los docentes resultaría errado, pues la duda debe recaer sobre las aseveraciones dadas en los reportes y no sobre las personas. Esto podría llevar a prejuicios que afectan la objetividad y pueden condicionar los resultados. En la Tabla 4 se muestran las justificaciones de la decisión de considerar el escepticismo profesional como un tema de confianza/ desconfianza, en el contexto de la duda presunta. 
TABLA 4

Opiniones de los docentes que perciben el escepticismo profesional como confianza - duda -

\begin{tabular}{|c|c|}
\hline Docente & Opinión \\
\hline Docente 1 & $\begin{array}{l}\text { "Creo que el rol del auditor debería estar para cumplir con su } \\
\text { escepticismo profesional basado en la desconfianza que no crea } \\
\text { que todo está sucediendo". }\end{array}$ \\
\hline Docente 3 & $\begin{array}{l}\text { "El tema de confianza también tiene que ver con el papel que } \\
\text { cumple el auditor, porque el auditor tiene que ser por naturaleza } \\
\text { escéptico (...). Porque está cumpliendo una función en la que un } \\
\text { tercero le ha encomendado. Una función de verificación de } \\
\text { evaluación y de juicio profesional, y ese tercero no tiene } \\
\text { posibilidades de sesgar el conocimiento que el auditor ha tenido } \\
\text { siempre, entonces mal haria en defraudar el encargo que le han } \\
\text { hecho a partir de relaciones que lo hagan ser mucho más } \\
\text { complaciente con la administración". }\end{array}$ \\
\hline Docente 6 & $\begin{array}{l}\text { "En mi opinión parte de la confianza, yo diría que sí es confianza, } \\
\text { cuando yo empecé en la auditoría a mí me enseñaron que tengo } \\
\text { que ser desconfiado de todo (...) porque es que uno actúa en base } \\
\text { de lo que va viendo, en lo que va encontrando". }\end{array}$ \\
\hline Docente 13 & $\begin{array}{l}\text { "Creo que el escepticismo es desconfiar de todo el mundo, pues en } \\
\text { mi opinión, no voy a llegar a un buen trabajo de auditoria, hay que } \\
\text { llegar, pero la idea no es desconfiar, ni de atacar el trabajo del } \\
\text { otro, pero yo creo que más que la confianza o desconfianza, es el } \\
\text { respeto que debe tener por la otra persona". }\end{array}$ \\
\hline Docente 15 & "Es desconfiar de la cabeza de la administración". \\
\hline
\end{tabular}

Fuente: elaboración propia con base en los resultados de las entrevistas.

Los entrevistados se enfocan en la desconfianza a las personas que preparan y presentan la información financiera. Esto podría entenderse como parte de lo que Nelson (2009) denomina información. No obstante, una posición prejuiciada de desconfiar de todos y de todo se aleja de la objetividad al evaluar las evidencias. Se resalta que los participantes consideran aspectos como "complacer a la gerencia". Esto puede relacionarse con los incentivos, los cuales requieren de una fuerte condición ética para la toma de decisiones, es decir, para la acción escéptica (Nelson, 2009). Uno de los entrevistados (docente 6) informa que le "enseñaron a desconfiar de todo", lo que indica que la postura del docente influye en la conducta del profesional.

Dos docentes (docentes 4 y 10) no se identificaron en ninguna tendencia. Ellos justifican su posición en que el escepticismo es intrínseco al auditor, y lo relacionan con los métodos que el auditor puede construir. Es decir, a semejanza de una investigación, utilizando hipótesis y falsearlas. En la tabla 5 se presenta la justificación de los docentes para no escoger ninguna de las dos tendencias.

TABLA 5

Docentes que no se identifican en ninguna de las dos tendencias de escepticismo profesional

\begin{tabular}{|c|l|}
\hline Docente & \multicolumn{1}{c|}{ Opinión } \\
\hline Docente 4 & $\begin{array}{l}\text { "El escepticismo debe ser natural al trabajo del auditor, en } \\
\text { la medida que el auditor es un investigador, él tiene que } \\
\text { plantearse y cambiar los métodos tradicionales de auditoria } \\
\text { por métodos de investigación donde él puede construir } \\
\text { hipótesis y puede ir a falsear esas hipótesis para demostrar } \\
\text { que, como se hace en cualquier investigación no hay } \\
\text { suficiente evidencia para decir que, y no al contrario". }\end{array}$ \\
\hline Docente 10 & $\begin{array}{l}\text { "Para mí el escepticismo es una cuestión de método, no es } \\
\text { una cuestión de que si yo confio o desconfio de un cliente } \\
\text { (...), para poder identificar incorrecciones materiales yo } \\
\text { tengo que encontrar las zonas en las que más } \\
\text { probablemente hubiera habido un error, entonces supone } \\
\text { una reflexión, es una manera de ver las cosas, es una } \\
\text { actitud, es puro método, es la manera como hago la } \\
\text { auditoria". }\end{array}$ \\
\hline
\end{tabular}

Fuente: elaboración propia con base en los resultados de las entrevistas.

Ambos docentes reconocen la necesidad del escepticismo profesional, pero se enfocan en lo procedimental. El docente 4 concibe el escepticismo como algo natural en el auditor y plantea como método la construcción de hipótesis y la falsación. 
El docente 10 concibe el escepticismo como un método para identificar inconsistencias en la información. Estas posturas ameritan una investigación separada, pero para las investigadoras, enfocarse solo en el método minimiza la importancia de la discusión sobre el escepticismo profesional.

El docente 11 considera que el escepticismo es una combinación de posición de confianza del auditor y sus actitudes profesionales. El docente argumenta que existe un aspecto moral en la decisión, el cual se ve influido por diversas circunstancias, así como un tema de personalidad del auditor, lo que hace que existan diferentes perfiles de auditor. En la tabla 6 se muestra la justificación del docente para decidir que se encuentra entre ambas tendencias.

TABLA 6

Opinión del docente que se adhiere a las dos corrientes y percibe el escepticismo profesional como confianza y como cualidad profesional

\begin{tabular}{|l|l|}
\hline \multicolumn{1}{|c|}{ Docente } & \multicolumn{1}{c|}{ Opinión } \\
\hline & $\begin{array}{l}\text { "El escepticismo-como hemos dicho- es un } \\
\text { dilema, y pues ser visto desde el lado negativo } \\
\text { como desconfianza, y desde el lado positivo como } \\
\text { confianza (...) Si es de confianza es desde el } \\
\text { punto de vista moral, si es de cualidad estamos } \\
\text { hablando de la psicología, o sea de la persona, } \\
\text { (..), la parte objetiva del trabajo es donde el } \\
\text { contador es capaz de desarrollar la confianza". }\end{array}$ \\
\hline
\end{tabular}

Fuente: elaboración propia con base en los resultados de las entrevistas.

La opinión mencionada anteriormente propone una visión de las tendencias como complementarias. Cada una de ellas cubre los posibles vacíos que la otra no desarrolla. El docente resalta los posibles dilemas que pueden presentarse en el desarrollo de la auditoría, por lo que no descarta el uso de las dos corrientes de forma simultánea.

Como se observa en los resultados expuestos, no existe un consenso en las concepciones del escepticismo profesional, lo cual ratifica lo expresado por diversos autores como Hurtt et al. (2013), Nelson (2009), Quadackers (2009), Liu (2018), Viloria (2013, 2016). Al no tener consensos en la concepción del escepticismo profesional y su aplicación, la formación del contador público se ve afectada por esta ambigüedad. Llama la atención que los docentes entrevistados no asocian el escepticismo profesional con lo establecido en el campo normativo de la actitud de mente inquieta y cuestionadora, sino más bien con una característica de la personalidad del sujeto.

$\mathrm{Al}$ reconocer el escepticismo como una parte de la personalidad del sujeto, la formación del profesional en las instituciones de educación superior debería fomentar ejes curriculares en los que puedan fortalecerse algunas características que propendan a la mentalidad cuestionadora. De esta manera, estarían siguiendo la normativa actual al respecto.

Al no estar claramente establecidos los parámetros del escepticismo profesional, el proceso educativo puede tender a minimizarlo. Esto explicaría por qué diferentes consejos y comités que emiten normas profesionales estén realizando esfuerzos importantes al respecto.

Una vez segmentadas las tendencias de los docentes, se solicitó que escogieran entre una lista las características que definían una u otra tendencia, y que son necesarias para la propuesta de formación, reforzamiento o mejora de la enseñanza del escepticismo en las aulas de clases. Las listas se dividieron igualmente por tendencias. Los docentes contestaban en función de la que habían escogido inicialmente, indicando todas con las que estaban de acuerdo o desacuerdo.

Los cinco docentes que se identificaron con la tendencia de confianza/desconfianza, relacionada con la duda presunta, coinciden en características como: motivación de conocer a su cliente, evaluación de riesgos, modo de pensar forense, capacidad de identificación y resolución de problemas, e identificación de declaraciones falsas. En la tabla 7 se muestran sus respuestas, en frecuencia absoluta de los docentes. 
TABLA 7

Características del escepticismo profesional desde la percepción de confianza

\begin{tabular}{|l|c|c|}
\hline \multicolumn{1}{|c|}{ Aspectos } & $\begin{array}{c}\text { Desacuerdo } \\
\text { Frecuencia } \\
\text { Absoluta }\end{array}$ & $\begin{array}{c}\text { Acuerdo } \\
\text { Frecuencia } \\
\text { Absoluta }\end{array}$ \\
\hline $\begin{array}{l}\text { Alta motivación para conocer previamente a } \\
\text { su cliente }\end{array}$ & 1 & 4 \\
\hline $\begin{array}{l}\text { Alta evaluación de riesgos y enlace con la } \\
\text { planificación de auditoria }\end{array}$ & & 5 \\
\hline $\begin{array}{l}\text { Modo de pensar "forense" (alta duda sobre la } \\
\text { veracidad de las pruebas) }\end{array}$ & 2 & 5 \\
\hline Capacidad de resolución de problemas & & 3 \\
\hline $\begin{array}{l}\text { Capacidad para identificar potenciales } \\
\text { declaraciones falsas de la gerencia }\end{array}$ & & 5 \\
\hline $\begin{array}{l}\text { Reconocimiento de incentivos que atentan } \\
\text { contra la ética profesional }\end{array}$ & 1 & 4 \\
\hline
\end{tabular}

Fuente: elaboración propia con base en los resultados de las entrevistas y características de Nelson (2009).

Se observa que, a pesar que la mayoría está de acuerdo con todas las características, existen tres en las que coinciden los cinco docentes: alta evaluación de riesgos y enlaces con la planificación, modo de pensar forense e identificar declaraciones falsas. Esto es consistente con su percepción del escepticismo como confianza. Desde esta perspectiva, un profesional cuidará los niveles de riesgos de auditoria y estará atento a las inconsistencias para detectar declaraciones falsas. En la docencia se hará énfasis en la creencia de que se debe desconfiar de todas las declaraciones de la gerencia, así como acumular un número importante de pruebas para alcanzar las evidencias suficientes y competentes.

Igualmente, al grupo de los docentes que percibieron el escepticismo profesional como una actitud personal (seis docentes), se les solicitó que seleccionaran las características más representativas que debería tener un profesional contable. Ellos coinciden mayoritariamente en aspectos como: curiosidad, entendimiento interpersonal, cuestionamiento, autodeterminación y capacidad de deliberación. En la tabla 8 se muestran las respuestas.

TABLA 8

Características de escepticismo profesional relacionadas con actitud personal

\begin{tabular}{|l|c|c|}
\hline \multicolumn{1}{|c|}{ Caracteristicas } & $\begin{array}{c}\text { Desacuerdo } \\
\text { Frecuencia } \\
\text { Absoluta }\end{array}$ & $\begin{array}{c}\text { Acuerdo } \\
\text { Frecuencia } \\
\text { Absoluta }\end{array}$ \\
\hline Curiosidad & 1 & 5 \\
\hline Confianza en sí mismo & 1 & \\
\hline Entendimiento interpersonal & & 5 \\
\hline Cuestionamiento & & 5 \\
\hline Autodeterminación & & 5 \\
\hline Deliberación & & 5 \\
\hline
\end{tabular}

Fuente: elaboración propia con base en los resultados de las entrevistas y Hurtt et al. (2002, 2010).

En general, los docentes se identifican con las características propuestas por Hurtt et al. (2002, 2010, 2013). Esto implica que el docente debe utilizar estrategias para desarrollar estas características, como, por ejemplo, el trabajo en equipo para afianzar relaciones interpersonales, o los debates en clases para la capacidad deliberativa.

En este grupo, el docente 5 argumentó su desacuerdo en dos características: la curiosidad y confianza en sí mismo. El docente expresa que la curiosidad se trata más de una postura personal que un elemento del escepticismo, mientras que la confianza no se trata de un problema de la persona, sino de la confianza en la información. Sin duda, el entrevistado considera que estas características son subjetivas y se contraponen a la objetividad, así como a salvaguardar la veracidad de la información. Sin embargo, desde la postura de mentalidad inquieta, que se asocia a las cualidades personales, la curiosidad puede ser afianzada como una forma de cuestionamiento. Buscar la razón de los sucesos y la confianza en sí mismo, son características indispensables para desarrollar relaciones interpersonales, trabajo en equipo y capacidad deliberativa. 
A todos los docentes se les pidió que indicarán características que pudieran desarrollarse en la formación del escepticismo profesional, distintas a las propuestas por cada tendencia. Cada docente listó una serie de característica que podrían formarse en el estudiante de contaduría pública. En la tabla 9 se pueden observar las características propuestas.

TABLA 9

Características que podrían desarrollar escepticismo profesional en el contador público

\begin{tabular}{|c|c|}
\hline Docente & Característica propuesta \\
\hline Docente 1 & $\begin{array}{l}\text { Independencia mental } \\
\text { Comunicación asertiva }\end{array}$ \\
\hline Docente 2 & Comprensión del marco estratégico de la organización. \\
\hline Docente 3 & $\begin{array}{l}\text { Debe ser Autocritico } \\
\text { Individual (autónomo) }\end{array}$ \\
\hline Docente 4 & $\begin{array}{l}\text { Investigador } \\
\text { Capacidad de inferir situaciones }\end{array}$ \\
\hline Docente 5 & $\begin{array}{l}\text { Actitud crítica, un juicio profesional que lleve conocimiento, } \\
\text { experiencia, Habilidad intelectual de investigación. } \\
\text { Fuertes valores éticos }\end{array}$ \\
\hline Docente 6 & $\begin{array}{l}\text { Actitud mental indagadora } \\
\text { Juicio objetivo } \\
\text { Autoevaluación }\end{array}$ \\
\hline Docente 7 & $\begin{array}{l}\text { Experiencia } \\
\text { Independencia mental } \\
\text { No puede ser juez y parte (objetividad) } \\
\text { Juicio profesional } \\
\text { Efectividad } \\
\text { Transparencia }\end{array}$ \\
\hline Docente 8 & Independencia \\
\hline Docente 9 & Auto reflexivo, Constructivista (capacitación continua) \\
\hline Docente 10 & $\begin{array}{l}\text { Conocer cómo se espera que sean las cosas, comprobar las } \\
\text { realidades frente al criterio. } \\
\text { Obtener evidencia } \\
\text { Capacidad de análisis (ponderación, critica) }\end{array}$ \\
\hline Docente 11 & $\begin{array}{l}\text { Alta calidad en el trabajo } \\
\text { Construir una imagen del auditor de calidad } \\
\text { Comunicación corporal } \\
\text { Cualificación permanente, actualización permanente y educación }\end{array}$ \\
\hline Docente 12 & $\begin{array}{l}\text { Determinante } \\
\text { Alta capacidad critica } \\
\text { Alta compresión y análisis de lectura } \\
\text { Objetividad } \\
\text { Independencia mental } \\
\text { Suspicacia }\end{array}$ \\
\hline Docente 13 & $\begin{array}{l}\text { Un criterio ético elevado } \\
\text { Solicitar más y mayores explicaciones al cliente (indagatoria) } \\
\text { Calificar las tendencias actuales del negocio }\end{array}$ \\
\hline Docente 14 & No contestó \\
\hline Docente 15 & $\begin{array}{l}\text { Capacitación permanente } \\
\text { Experiencia } \\
\text { Trabajo de calidad }\end{array}$ \\
\hline
\end{tabular}

Fuente: elaboración propia con base en los resultados de las entrevistas.

Las características propuestas para desarrollar el escepticismo profesional en el auditor se acercan más al modelo de determinantes de Nelson (2009) que al modelo de Hurtt et al. (2002, 2010, 2013). Es decir, se trata de características que relacionan aspectos de la personalidad con externalidades que inciden en el juicio profesional, así como el manejo de incentivos. En otras palabras, parte de los entrevistados coinciden en que, al aplicar el escepticismo profesional, se requieren características propias de la personalidad que influyen en la conducta de cada persona, así como habilidades para conectarse con el entorno y fortalezas éticas para la toma de decisiones. No se trata de que una persona posea todas las características, sino que su formación le permita contar con las habilidades y herramientas para actuar con escepticismo profesional, en cualquier situación.

A todos los entrevistados se les pidió que aportaran estrategias para la formación del escepticismo profesional en las aulas de clase. En cuanto a las estrategias para motivar el escepticismo profesional en las aulas universitarias, en la tabla 10 se observan las propuestas. 
TABLA 10

Estrategias propuestas para motivar el escepticismo profesional en el aula

\begin{tabular}{|c|c|}
\hline Docente & Caracteristica propuesta \\
\hline Docente 1 & $\begin{array}{l}\text { Independencia mental } \\
\text { Comunicación asertiva }\end{array}$ \\
\hline Docente 2 & Comprensión del marco estratégico de la organización. \\
\hline Docente 3 & $\begin{array}{l}\text { Debe ser Autocritico } \\
\text { Individual (autónomo) }\end{array}$ \\
\hline Docente 4 & $\begin{array}{l}\text { Investigador } \\
\text { Capacidad de inferir situaciones }\end{array}$ \\
\hline Docente 5 & $\begin{array}{l}\text { Actitud crítica, un juicio profesional que lleve conocimiento, } \\
\text { experiencia, Habilidad intelectual de investigación. } \\
\text { Fuertes valores éticos }\end{array}$ \\
\hline Docente 6 & $\begin{array}{l}\text { Actitud mental indagadora } \\
\text { Juicio objetivo } \\
\text { Autoevaluación }\end{array}$ \\
\hline Docente 7 & $\begin{array}{l}\text { Experiencia } \\
\text { Independencia mental } \\
\text { No puede ser juez y parte (objetividad) } \\
\text { Juicio profesional } \\
\text { Efectividad } \\
\text { Transparencia }\end{array}$ \\
\hline Docente 8 & Independencia \\
\hline Docente 9 & Auto reflexivo, Constructivista (capacitación continua) \\
\hline Docente 10 & $\begin{array}{l}\text { Conocer cómo se espera que sean las cosas, comprobar las } \\
\text { realidades frente al criterio. } \\
\text { Obtener evidencia } \\
\text { Capacidad de análisis (ponderación, critica) }\end{array}$ \\
\hline Docente 11 & $\begin{array}{l}\text { Alta calidad en el trabajo } \\
\text { Construir una imagen del auditor de calidad } \\
\text { Comunicación corporal } \\
\text { Cualificación permanente, actualización permanente y educación }\end{array}$ \\
\hline Docente 12 & $\begin{array}{l}\text { Determinante } \\
\text { Alta capacidad critica } \\
\text { Alta compresión y análisis de lectura } \\
\text { Objetividad } \\
\text { Independencia mental } \\
\text { Suspicacia }\end{array}$ \\
\hline Docente 13 & $\begin{array}{l}\text { Un criterio ético elevado } \\
\text { Solicitar más y mayores explicaciones al cliente (indagatoria) } \\
\text { Calificar las tendencias actuales del negocio }\end{array}$ \\
\hline Docente 14 & No contestó \\
\hline Docente 15 & $\begin{array}{l}\text { Capacitación permanente } \\
\text { Experiencia } \\
\text { Trabajo de calidad }\end{array}$ \\
\hline
\end{tabular}

Fuente: elaboración propia con base en los resultados de las entrevistas.

No existen diferencias marcadas de las estrategias entre los grupos de quienes entienden el escepticismo profesional como mentalidad cuestionadora (cualidades personales) y los que lo conciben como duda presunta (confianza/desconfianza). Los docentes se inclinan por el estudio de casos como estrategia de aula. Esto desde dos orientaciones: un grupo de entrevistados lo propone como reforzamiento ético, y el otro como vinculación a otros saberes como la estadística y la teoría de la argumentación. Ambas posiciones pueden vincularse porque el escepticismo requiere de conocimientos, habilidades y conducta ética. El resultado es coherente, considerando que la apropiación de casos reales es una manera de acercar al estudiante a la comprensión del escepticismo profesional y como aplicarlo.

Otra estrategia aportada es el juego de roles, en los que unos sean clientes y otros auditores. Esto debe generar debates en los que se fomente el pensamiento crítico y argumentativo frente a la oposición, lo cual confronta al aprendiz para madurar su personalidad y evaluar los conocimientos previos en el aula.

Estas dos estrategias pueden desarrollarse en aula y también son recomendadas por las NIE (2019). Sin embargo, seguramente la forma y los resultados de los casos y juegos de roles dependerá de la concepción de escepticismo del docente. Así, por ejemplo, el docente 2, que se identifica con la mentalidad cuestionadora, entiende que el objetivo de estos ejercicios es formar el pensamiento crítico. Por su parte, los docentes que se identifican con la duda presunta inclinan el objetivo de los estudios de casos y juegos de roles hacia los conflictos éticos, la evaluación de riesgos de auditoría o el estudio de leyes antifraude. El docente 1, por ejemplo, plantea la necesidad de fortalecer, a través del estudio de casos, lo aspectos éticos que sustentan las decisiones del auditor.

Los docentes 9, 10, 11 y 14 se diferencian del resto al proponer una revisión curricular. El docente 9 se inclina por implementar en los diferentes espacios académicos el desarrollo del escepticismo profesional como núcleo temático, articulado con los demás temas propios de la asignatura. De esta manera, el escepticismo curricular no estaría asociado solo a materias como la ética profesional, sino que se reconocería su debida importancia en toda la malla curricular. Por su parte, el docente 10 se inclina por el estudio de las teorías 
contables. El docente 11 propone la inclusión en el currículo de temas de filosofía, y la creación de grados académicos (maestrías y doctorados). Finalmente, el docente 14 apuesta por fortalecer la investigación. La propuesta de incidir en el currículo de contaduría pública se dirige más allá de la acción puntual en aula y representa la posibilidad de un cambio real de la situación que se presenta al no tener incorporado el escepticismo profesional en el proceso de formación.

\section{Conclusiones}

El escepticismo profesional en la contaduría pública es un concepto fundamental que afecta la conducta de los profesionales. Entes emisores de normativa internacional han planteado la necesidad de revisar toda la normativa para incorporarlo como un eje transversal. Esto se debe a que, a pesar de mencionarse en muchos de los estándares, no se ha desarrollado suficientemente como para poder aplicarlo de forma adecuada y explicarlo en los estándares de educación.

Por su parte, los investigadores presentan posturas diferenciadas. En el caso de la mentalidad cuestionadora, relacionan el escepticismo profesional con cualidades personales que pueden fomentarse en los procesos educativos del profesional para fortalecer la conducta escéptica. En el caso de la duda presunta, el escepticismo se relaciona con información, personalidad e incentivos. Desde esta postura la formación debe fortalecer el manejo de los incentivos para condicionar un juicio y acciones escépticas adecuadas.

$\mathrm{Al}$ entrevistar a los docentes, se inclinan por la concepción del escepticismo profesional de mentalidad cuestionadora, que se relaciona con las cualidades de personalidad. Sin embargo, estas no son asociadas con cualidades personales, sino como un pre-requisito para ser auditor. Estos participantes coinciden en las cualidades personales como la confianza en sí mismo, el entendimiento interpersonal, el cuestionamiento, la deliberación y la autodeterminación, lo que apoya la postura de Hurtt et al. (2002, 2008, 2010). Un entrevistado no coincide con dos cualidades: la curiosidad y la confianza en sí mismo, por considerarlas subjetivas.

Los docentes que se identifican con la postura de duda presunta se justifican en la desconfianza de las personas que preparan y presentan la información financiera. Sin embargo, esto puede afectar la objetividad del trabajo del auditor al prejuzgar sus actuaciones. Estos participantes coinciden en las características de un profesional escéptico, propuestas por Nelson (2009) como el que evalúa altamente los riesgos, tiene un modo de pensar forense y detecta declaraciones falsas. Uno de los entrevistados reconoce que su entendimiento del escepticismo como desconfianza parte de cómo lo formaron, lo cual es un indicativo de la incidencia del proceso de enseñanza-aprendizaje en los profesionales.

Ninguno de los docentes relaciona el escepticismo a lo prescrito en la normativa internacional sobre la mente inquieta, lo que indica que deben hacerse mayores esfuerzos para su apropiación. En cuanto a otras características de un profesional escéptico, los entrevistados incluyeron aspectos relacionados de las dos posturas. Esta situación parece indicar que el escepticismo profesional es una combinatoria de diferentes aspectos, incluyendo a los principios éticos y a posturas que se entrecruzan. Esto amplia lo propuesto tanto por los investigadores referenciados como por la normativa internacional.

Las estrategias de aula que los participantes proponen se centran en el estudio de casos y el juego de roles. No obstante, los objetivos de estas se diferencian según la posición de los docentes, en cuanto a la concepción del escepticismo profesional. Los docentes identificados con la actitud de mentalidad inquieta se enfocan en el desarrollo del pensamiento crítico, mientras que los docentes más identificados con la duda presunta se enfocan en los dilemas éticos, la evaluación de riesgos y las discusiones de temas como el fraude.

Se percibe como el conocimiento y aplicación del escepticismo profesional del docente permea la formación del estudiante y futuro profesional. Por ello, es importante que los docentes que orientan las auditorías y aseguramiento de la información tengan fundamentos teóricos y prácticos sobre el uso adecuado 
del escepticismo profesional, considerando la normatividad internacional para la formación del profesional global.

La otra estrategia que, a criterio de las investigadoras es fundamental, es la adecuación formativa para incluir como eje curricular el escepticismo profesional en interrelación con el plan de estudios de la carrera. Igualmente, debe ser considerada la vinculación del escepticismo profesional con los aspectos éticos, los valores y los procesos investigativos que son parte de la metodología de un encargo de aseguramiento. Una revisión curricular que parta de los ejes de comportamiento profesional, el juicio y el escepticismo, fortalecería las conductas adecuadas del contador público.

Las Universidades tienen un papel ineludible en la formación y educación continua del contador público. No solamente se requiere un esfuerzo en las competencias técnicas y habilidades profesionales, sino también en el reforzamiento de las bases de la conducta profesional.

\section{Referencias}

Consejo de Estándares de Educación - IAESB (2018). Accounting Education Insights How can we become better skeptics? https://www.iaesb.org/publications/accounting-education-insights-how-can-we-become-better-skeptics

Consejo de Estándares de Educación - IAESB. (2019). Manual de Pronunciamientos Internacionales de Formación. Londres: IFAC.

Consejo de Normas Internacionales de Auditoría y Aseguramiento - IAASB. (2017). Manual de procedimientos internacionales de control de calidad, auditorias, revisión, otros encargos de aseguramiento, y servicios relacionados. http://www.iaasb.org/system/files/publications/files/ESP_IAASB_HB2016-2017_Vol_I_0.pdf

Consejo de Normas Internacionales de Ética para Contadores - IESBA (2018). Código Internacional de Ética para Profesionales de la Contabilidad (incluidas Normas Internacionales de Independencia). Londres: IFAC.

Federación Internacional de Contadores - IFAC (2017). Strengthening the Pillars of Professional Skepticism. Observations of the IAASB-IAESB-IESBA Professional Skepticism Working Group. Londres: IFAC. https://www.iaasb.org/system/files/meetings/files/20170619-IAASB-Agenda_Item_9-B_Joint_Profes sional_Skepticism_Publication-Final.pdf

Glover, S., \& Prawitt, D. (2014). Enhancing auditor professional skepticism: The professional skepticism continuum. Current Issues in Auditing, 8(2), 1-10. http://www.aajournals.org/doi/full/10.2308/ciia-50895?code=aaan-si te

Hurtt, K., Brown-Liburd, H., Earley, C., \& Ganesh, K. (2013). Research on Auditor Professional Skepticism: Literature Synthesis and Opportunities for Future Research. Auditing: A Journal of Practice \& Theory American Accounting Association, 32(Suppl. 1). 45-97. http://aaapubs.org/doi/abs/10.2308/ajpt-50361

Hurtt, K., Eining, M., \& Plumlee, D. (2002). Professional Skepticism: A Model with Implications for Research, Practice and Education. Documento de Trabajo. University of Wisconsin - Madison. www.business.utah.edu

Hurtt, K., Eining, M., \& Plumlee, D. (2008). An Experimental Examination of Professional Skepticism. SSRN Electronic Journal. https://www.researchgate.net/publication/228307269

Hurtt, K., Eining, M., \& Plumlee, D. (2010). Linking professional skepticism To auditors' behaviors. http://aaahq.org /western

Libby, R., \& Luft, J. (1993). Determinants of judgment performance in accounting settings: Ability, knowledge, motivation, and environment. Accounting, Organizations and Society, 18(5). https://www.sciencedirect.com/ science/article/pii/036136829390040D

Liu, X. (2018). Can professional skepticism be Learned? Evidence from China. Journal of Education for Business, 93(6), 265-275. http://www.tandfonline.com/loi/vjeb20

McCoy, N., Burnett, R. D., Friedman, M. E., \& Morris, M. (2011). Internal audit: How to develop professional skepticism. Journal of Corporate Accounting \& Finance (Wiley), 22(4), 3-14. https://onlinelibrary.wiley.com/d oi/pdf/10.1002/jcaf.20684 
Nelson, M. (2009). A Model and Literature Review of Professional Skepticism in Auditing. Auditing. A Journal of Practice \& Theory, 28(2). 1-34. http://aaapubs.org/doi/10.2308/aud.2009.28.2.1 ?code=aaan-site

Quadackers, L. (2009). Study of Auditors' Skeptical Characteristics and Their Relationship to Skeptical Judgments and Decisions. Tesis Doctoral. Alemania: Vrije Universiteit. https://research.vu.nl/ws/portalfiles/portal/4218 0914/complete+dissertation.pdf

Viloria, N. (2013). El escepticismo profesional: Estrategias de aula para los estudiantes de contaduría. Actualidad Contable FACES, 16(2), 112-134.

Viloria, N. (2016). Estrategias de reforzamiento de escepticismo profesional para los contadores públicos en actividad de auditoría. Actualidad Contable FACES, 19(33), 102-119.

\section{Notas}

* Artículo de investigación científica.

\section{Licencia Creative Commons CC BY 4.0}

Para citar este articulo: Viloria O., N., \& Espinosa D., Y. S. (2020). El escepticismo profesional del auditor. Una visión desde los docentes de contaduría pública colombianos. Cuadernos de Contabilidad, 21. https:// doi.org/10.11144/Javeriana.cc21.epav 